DOI: $10.15593 / 2224-9982 / 2021.65 .06$

УДК: 621.791

\author{
Ю.В. Цветков ${ }^{1}$, М.А. Савин ${ }^{2}$, В.Д. Василенко ${ }^{2}$, \\ Г.А. Цветков ${ }^{2}$, Е.И. Вахрамеев ${ }^{2}$ \\ ${ }^{1}$ Малое инновационное предприятие «Инновации», Пермь, Россия \\ ${ }^{2}$ Пермский национальный исследовательский политехнический \\ университет, Пермь, Россия

\section{ЧИСЛЕННОЕ МОДЕЛИРОВАНИЕ ПРОЦЕССА РЕЗКИ МАТЕРИАЛА КИСЛОРОДНЫМ КОПЬЕМ}

\begin{abstract}
Разделительная резка различных материалов и конструкций, в особенности крупногабаритных и толстостенных, всегда была и остается актуальной проблемой в промышленности. Одним из высокоэффективных и наименее затратных способов резки является резка кислородным копьем. Приводится краткий обзор способов разделительной резки, а также оценочные исследования эффективности резки кислородными копьями. Ставится математическая и численная модель в двух постановках: подробной, включающей расчет течения кислорода в трубке копья, и упрощенной, использующей вместо копья подвижный тепловой источник. Приводятся основные гипотезы и допущения для упрощенной модели, а также демонстрируется составление граничных условий в соответствии с теорией подобия теплообменных процессов. Дается оценка трудоемкости моделирования и приводятся результаты расчета процесса разделительной резки кислородным копьем листа стали, латуни и оксида алюминия. Основными целями расчетов является качественный анализ процессов, валидация численной модели, а также определение ориентировочного времени разрезания образцов. В ходе расчетов, помимо времени разрезания, анализируется тепловой поток, поглощаемый образцом и количество теплоты, затраченное на фазовый переход (из твердого состояния в жидкое). Критерием качественной оценки полученных расчетным путем результатов являются огневые испытания, проведенные с экспериментальными кислородными копьями. Дается краткое пояснение и описание огневых испытаний, а также результатов разделительной резки трубки и пластины из нержавеющей стали. Оценены время и скорость резания. Помимо этого, на одном из образцов для резки показана эффективность использования экспериментального копья (с проволочным сердечником) по сравнению с традиционным кислородным резаком.

Ключевые слова: кислородное копье, численное моделирование, огневые испытания, модель VOF, разделительная резка, конечно-объемная модель, фазовые переходы, плавление, затвердевание, топливная композиция, техническая эффрективность.
\end{abstract}

\author{
Ju.V. Tsvetkov' ${ }^{1}$ M.A. Savin'², V.D. Vasilenko², \\ G.A. Tsvetkov ${ }^{2}$, E.I. Vahrameev ${ }^{2}$ \\ ${ }^{1}$ Small Innovative Enterprise "Innovation", Perm, Russian Federation \\ ${ }^{2}$ Perm National Research Polytechnic University, Perm, Russian Federation
}

\title{
NUMERICAL MODELING OF THE OXYGEN LANCE CUTTING PROCESS
}

The material cutting is very important and actual industry problem. The oxygen lance cutting is one of the types of most efficiency and cheapest cutting methods. This article has short preview of material cutting methods and has evaluative researches of the oxygen lances cutting efficiency. Mathematical model and numerical model is created with two forms: full form with solving of oxygen flow in lance tube and short form with replace lance to surface heat source. Basic theses of the short form and boundary conditions creating with heat transfer theory are showed in the article. The analysis of modeling complexity is represented in the article and the article has numerical solution results of oxygen lance cutting process for steel plate, latten alloy and aluminium oxide plate. The main target of solutions is evaluative processes analysis, numerical model validation and calculation of the approximately prototypes cutting time. The prototype absorbed heat flux and the phase change heat (from solid to liquid) is analyzed in these calculations aside from the cutting time. The criterion of quality estimation for calculating results is firing tests for experimental oxygen lances. The article has short comment and the firing tests description with results of the steel tube and steel plate cutting. The cutting time and the cutting velocity was estimated. Additionally the experimental lance usage efficiency (with core rods) was showed for one of the prototypes. This efficiency was compared to the efficiency of traditional oxygen lance.

Keywords: oxygen lance, numerical modeling, firing tests, VOF-model, cutting, finite-volume model, phase changes, melting, solidification, fuel composition, technical efficiency. 
На сегодняшний день известны и доступны различные способы для разделительной резки металлических и неметаллических конструкций [1-6].

К этим способам относятся: механическая резка (с помощью стальных пил, отрезных абразивных кругов, ленточных инструментов, высокоскоростных металлических дисков), гидроабразивная резка, термическая и химическая резка с помощью кислородных резаков, а также разделительная резка с помощью взрывных шнуров.

Каждый из этих способов имеет свои особенности, достоинства и недостатки и в соответствии с ними находит свое практическое применение. Но в реальной жизни до сих пор не удается в полной мере охватить все возникающие потребности промышленности.

Исходя из этого, весьма актуальной задачей является совершенствование существующих и разработка новых способов и инструментов для разделительной резки, позволяющих осуществлять последнюю с высокой эффективностью и скоростью [7], что особенно важно, например, в чрезвычайных ситуациях [8].

Давно известен способ разделительной резки с помощью кислородного копья. Кислородное копье представляет собой трубку из стали, которую сжигают в струе кислорода, пропускаемого по ней. Факел горения (огневой пучок) подводят к изделию, которое необходимо разрезать, и путем расплавления материала производят ре $3^{1}[9,10]$.

Применение способа разделительной резки кислородным копьем носило и носит «экзотический» характер. Потенциальные возможности этого способа и его инструментарий не исследованы и, естественно, не используются в полной мере. Научно-технические и практические возможности кислородного копья как инструмента тепловой разделительной резки материалов в современной отечественной и зарубежной литературе описаны крайне скудно и зачастую носят сугубо прикладной характер $[7,8,11]$.

Ввиду этого в данной работе сделана попытка оценить эффективность кислородного копья как инструмента разделительной резки с

${ }^{1}$ РСН 343-86. Технология разрушения строительных конструкций при реконструкции промышленных предприятий / НИИСП Госстроя УССР. Изд. офиц. М., 1987. 81 с. помощью компьютерного моделирования процесса резки, а также сопоставить результаты моделирования с результатами натурных испытаний.

Поскольку резка кислородным копьем с точки зрения физических и химических процессов является довольно сложной, комплексной проблемой, то ее необходимо разбить на более простые части для глубокого и качественного изучения. В статье [12] была дана оценка характеру и режиму течения кислорода в различных конструкциях кислородных копий, а также исследован процесс сгорания копья при работе. Получены данные по продуктам сгорания и температурам горения.

На основании этих данных решено провести численное моделирование процесса резки для нескольких материалов и нескольких видов кислородных копий.

Поскольку обычное кислородное копье (в виде пустой трубки) не отличается высокой технической эффективностью [10], был рассмотрен его модифицированный вариант: трубка заполнена алюминиевыми и стальными проволоками в различном соотношении (рис. 1).

В данном случае в понятие технической эффективности работы кислородного копья включаются такие характеристики, как температура горения копья (температура огневого пучка) и суммарная теплопроизводительность рабочего процесса, определяемая массовым расходом продуктов сгорания и их теплофизическими свойствами (теплоемкость, теплопроводность химических соединений при различных температурах и агрегатных состояниях и др.).

Как было показано в работе [12], количество и материал проволок существенно влияют на температуру горения кислородного копья. Следовательно, как можно предположить, и на скорость резания материала, что и предстоит исследовать.

Исследования проведены для материалов, существенно отличающихся друг от друга по своим теплофизическим характеристикам: нержавеющая сталь $12 \mathrm{X} 18 \mathrm{H} 10 \mathrm{~T}$, латунь марки Л68, керамика $\left(\mathrm{Al}_{2} \mathrm{O}_{3}\right)$. При выборе материалов учтено, что именно они широко распространены в промышленности и во многих сферах производственной деятельности и именно эти материалы наиболее проблематичны для разрезания обычными способами и инструментами $[13,14]$. 

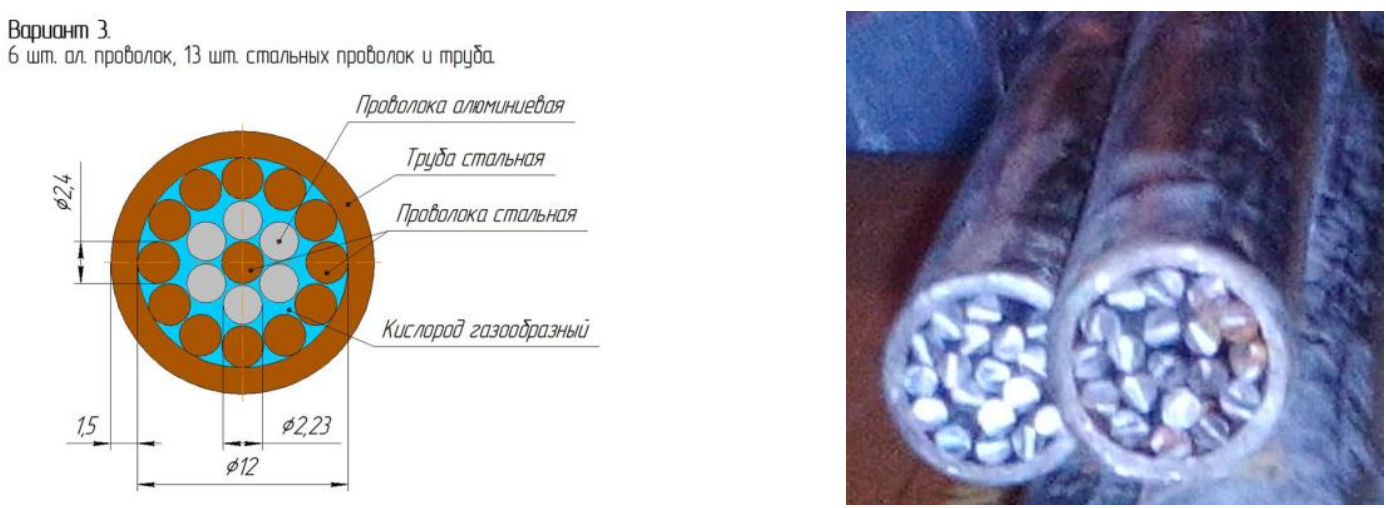

Рис. 1. Один из вариантов кислородного копья

Например, высоколегированная нержавеющая сталь $12 \mathrm{X} 18 \mathrm{H} 10 \mathrm{~T}$ - одна из самых распространенных в высокотехнологичном секторе промышленности: не поддается резанию обычным кислородным резаком в силу своей природы - «неокисляемости» (стойкости в среде кислорода даже при высоких температурах). Исходя из этого, кислородное копье, работающее по принципу тепловой резки, находит здесь свое эффективное применение.

При разработке модели для численных расчетов необходимо также учесть топливную композицию, иначе говоря, внутреннее наполнение кислородного копья. В нашем случае имеется три варианта топливной композиции: алюминиевые проволоки в стальной трубке копья, стальные проволоки в стальной трубке копья и смесь алюминиевых и стальных проволок в определенном соотношении опять же в стальной трубке.

Вначале предполагалось заложить в исходные данные для расчетно-теоретических исследований различные значения толщины образцов разрезаемых материалов, а именно 1,$0 ; 1,5 ; 2,0$ мм. Это позволило бы учесть особенности конструкций, в том числе и крупногабаритных; например из нержавеющих сталей или цветных металлов, как правило тонкостенных в силу их специальных эксплуатационных назначений. Но, как показали расчеты, с учетом принятых допущений и гипотез (будут описаны далее) необходимо остановиться на толщине образцов, равной 1 мм.

Численное моделирование процесса резки производилось на базе инженерного программного комплекса STAR-CCM+. Поскольку для задачи горения кислородного копья уже имеются термодинамические расчеты, снова рассматривать горение вместе с течением кислорода в копье не имеет смысла. Помимо этого, газодинамические сверхзвуковые течения и течения с высокими, но дозвуковыми скоростями в сложных каналах требуют мелкой конечно-объемной сетки для выполнения условия Куранта [15-17]. Это неизбежно повлечет за собой «утяжеление» модели и резкое увеличение времени расчетов и в то же время не даст каких-либо новых или значимых результатов.

Основными допущениями, принятыми для численного моделирования процесса резания кислородным копьем, являются следующие:

- моделирование теплообмена разрезаемого материала с окружающей средой с помощью граничных условий первого и второго рода (тепловых потоков);

- моделирование тепловой нагрузки на пластину в зоне предполагаемого контакта пламени и поверхности пластины с помощью заданной плотности теплового потока. Материал прогревается и, как следствие, прорезается движущимся тепловым источником;

- плотность материала в ходе расчета постоянная, вытекание расплава из зоны резания отсутствует;

- толщина разрезаемого материала равна 1 мм ввиду отсутствия потока массы в зону резания и, как следствие, выноса из нее расплава. Увеличение толщины приведет к получению крайне нефизичных результатов за счет термического сопротивления не удаленного из зоны резания расплава. 

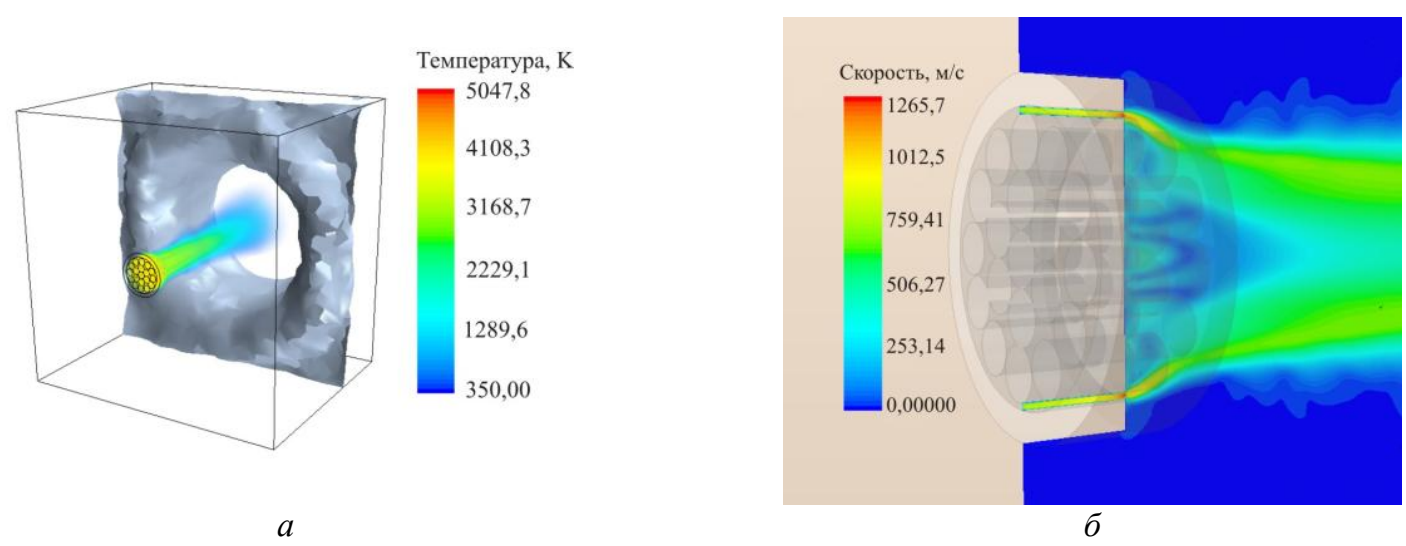

Рис. 2. Тестовое решение: $a$ - поле температур; $\sigma$ - поле скоростей

Для оценки скорости решения, сходимости решения и потенциальной возможности решения задачи без указанных допущений была проведена серия тестовых расчетов, а также поставлена задача разрезания стальной пластины кислородным копьем с учетом истечения газа (продуктов сгорания) из каналов копья, их взаимодействия с пластиной и окружающим воздухом.

Ввиду сложной геометрии канала кислородного копья и сверхзвуковых скоростей истечения продуктов сгорания на выходе максимальный допустимый шаг по времени для сходимости расчета составил (1E-5) с. При этом количество контрольных объемов расчетной области составило 1,2 млн. При многократном увеличении числа контрольных объемов (порядка 11 млн и более) можно использовать довольно существенные шаги по времени (порядка (1E-3)-(1E-1) с), но физическое время счета в этой ситуации заметно возрастет.

В тестовой, подробной, модели, результаты расчета которой представлены на рис. 2 , прожигалась пластина из алюминия толщиной 2 см, окруженная воздухом с температурой 300 К. Копье находилось на расстоянии 6 см от пластины и имело начальную температуру 3960 К и расход кислорода, равный 0,0036 кг/с. При таких условиях, по расчетам, алюминиевая пластина прогорает менее чем за секунду с образованием широкого пятна в области реза (см. рис. 2, б).

Несмотря на то, что задача в подобной постановке успешно решаема, скорость ее решения и устойчивость процесса решения недостаточны. Помимо этого, значительную часть времени занимает подготовка модели (построение качественной сетки, подбор числа призматических элементов вдоль границ в зависимости от ожидаемой скорости течения и др.). Такая высокая трудоемкость не отвечает задаче качественной оценки процесса резания. Ввиду этого на базе подробной модели был создан ряд упрощенных моделей, для которых и получены описываемые в статье результаты.

Для всех вариантов упрощенной задачи физическая модель остается такой же, как и в подробной задаче, и основывается на использовании модели Volume of Fluid (VOF) с учетом плавления и затвердевания [18-20]. Использование такой модели для фазовых переходов предполагает, что контрольные объемы, на которые разбита расчетная область, при достижении определенной температуры (солидус-ликвидус) меняют свою фазу и теплофизические свойства. При этом геометрия расчетной области не меняется.

В соответствии с принятыми допущениями тепловой поток от кислородного копья моделируется суммой конвективной и радиационной составляющих [21]:

$$
\begin{gathered}
Q=\alpha F\left(T_{1}-T_{2}\right)+ \\
+\in_{0} c_{0} F\left(\left(\frac{T_{1}}{100}\right)^{4}-\left(\frac{T_{2}}{100}\right)^{4}\right),
\end{gathered}
$$

где $\alpha$ - коэффициент теплоотдачи; $F$ - площадь теплоотдающей поверхности; $\in_{0}$ - приведенная степень черноты; $c_{0}-$ коэффициент излучения абсолютно черного тела; $T_{1}$ - температура пламени; $T_{2}$ - температура поверхности материала. 
Коэффициент теплоотдачи найден в соответствии с критериальным уравнением турбулентного обтекания пластины [21]:

$$
\begin{gathered}
\mathrm{Nu}=0,037 \operatorname{Re}^{0,8} \operatorname{Pr}^{0,43} \cdot \in_{m} ; \\
\alpha=\frac{\mathrm{Nu} \cdot \lambda}{d},
\end{gathered}
$$

где $d$ - характерный размер (диаметр пятна контакта); $\epsilon_{m}$ - поправка на направление теплового потока. Поскольку для расчета используется условие плотности теплового потока, соотношение (1) в результате записывается без площади поверхности пятна.

Площадь поверхности пятна, иначе говоря, площадь движущегося источника, принята равной площади поперечного сечения цилиндра с диаметром, равным внутреннему диаметру трубы кислородного копья (12 мм).

Таким образом, коэффициент теплоотдачи, принятый для расчетов, равен $5348,8 \mathrm{BT} /\left(\mathrm{M}^{2} \cdot \mathrm{K}\right)$, при условии средней скорости истечения в $500 \mathrm{~m} / \mathrm{c}$ (при массовом расходе 0,0036 кг/с) и температуре продуктов сгорания $3960 \mathrm{~K}$, соответствующей горению алюминия в кислороде с соотношением $66,67 \%$ на $33,33 \%$.

Обратный тепловой поток, излучаемый границами разрезаемого материала при перегреве, записывается согласно закону Стефана Больцмана в виде

$$
Q=\epsilon_{0} c_{0} F\left(\left(\frac{T_{2}}{100}\right)^{4}-\left(\frac{T_{0}}{100}\right)^{4}\right)
$$

Здесь $T_{0}$ - температура окружающей среды, во всех вариантах расчетов равная $300 \mathrm{~K}$.

Свойства разрезаемых материалов [22-24] сведены в таблицу. Удельная теплоемкость и теплопроводность материалов задаются в виде полиномиальных зависимостей от температуры. В таблице для них приведены лишь крайние значения.

При определении скорости движения кислородного копья для всех материалов разрешались задачи резки одинарным, сдвоенным и строенным копьем. Такие расчеты проведены с целью установления оптимального числа копий, обеспечивающего максимальную скорость резания. На основании этого в дальнейшем можно будет рассмотреть возможность создания эквивалентного одинарного кислородного копья с трубкой большего диаметра.

Первым материалом для численных расчетов была выбрана сталь 12Х18Н10Т. Время проплавления листа до начала резания для любого количества копий $(1,2,3)$ составило 0,358 с. Время резания и, соответственно, скорость резания изменялись практически пропорционально числу кислородных копий (рис. 3). Величины использованного теплового потока в зависимости от числа кислородных

\begin{tabular}{|c|c|c|c|}
\hline Параметр & 12X18H10T & Латунь Л68 & Керамика $\mathrm{Al}_{2} \mathrm{O}_{3}$ \\
\hline Плотность, кг $/ \mathrm{M}^{3}$ & 7240 & 8550 & 3960 \\
\hline Динамическая вязкость, Па·с & 0,00543 & 0,0057 & 0,0584 \\
\hline Скрытая теплота плавления, Дж/кг & 277000 & 221000 & 288000 \\
\hline Температура солидуса, К & 1676,15 & 1182 & 2050 \\
\hline Температура ликвидуса, К & 1732,15 & 1211 & 2050 \\
\hline Удельная теплоемкость, Дж/(кг·К) & $450-750$ & $390-410$ & $775-1463$ \\
\hline Теплопроводность, Вт/(м·К) & $15-36,2$ & $101-195$ & $40-7$ \\
\hline
\end{tabular}
копий представлены на рис. 3, 6 .

Свойства материалов
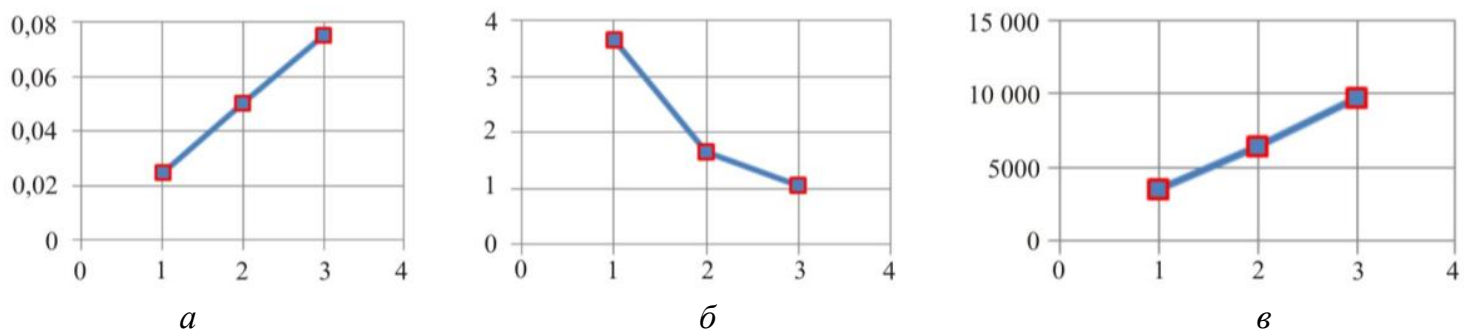

Рис. 3. Расчетные значения: $a$ - скорость (м/с); $\sigma$ - время (c); 6 - тепловой поток (Вт) 


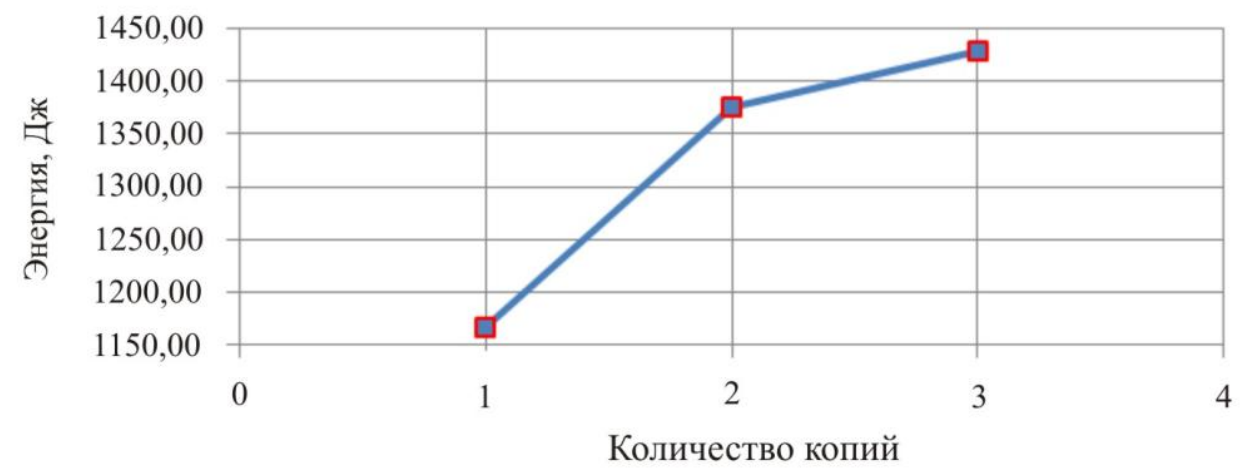

Рис. 4. Затраченная на фазовый переход энергия

В силу линейного увеличения площади поверхности контакта огневого пятна зависимость теплового потока также оказывается практически линейной.

Теплота, затраченная на переход стали из твердого состояния в жидкое, на момент окончания расчета, представлена на рис. 4. Объемы расплавленного материала для каждого варианта (1, 2 и 3 копья) равны соответственно $(7,1 \mathrm{E}-7) \mathrm{m}^{3},(8,37 \mathrm{E}-7) \mathrm{m}^{3},(8,69 \mathrm{E}-7) \mathrm{м}^{3}$.

При изменении топлива кислородного копья на смесь алюминия и железа в соотношении $50 \% / 16,67 \%$ температура сгорания смеси падает до 3364 К, следовательно, падает средний тепловой поток. Его значение становится на $30,2 \%$ меньше аналогичного случая при использовании в качестве топлива лишь алюминия. Эти изменения приводят к увеличению времени резания и времени проплавления, следовательно, уменьшается скорость резания. Она составила лишь $0,022 \mathrm{~m} / \mathrm{c}$, что на 3 мм/с меньше скорости резания в случае ис- пользования алюминиевых проволок внутри копья.

При моделировании резки стальной пластины копьями с железом в качестве горючего температура горения составила лишь 3118,4 К, что соответствует горению железа в кислороде с соотношением $80 \% / 20 \%$. В этом случае скорость резания стальной пластины имела наименьшее значение, равное 0,019 м/с. Для удобства все полученные результаты сведены в диаграммы на рис. 5.

Для варианта резания стальной пластины одинарным копьем приведены полевые картины фазового состояния и температур (рис. $6, a, \sigma)$ ). Из этих картин видно, что ширина реза получается сравнительно небольшой, так как из-за довольно высокой скорости резания (25 мм/с) металл на расстоянии диаметра от зоны резания не успевает прогреться даже до $700 \mathrm{~K}$.

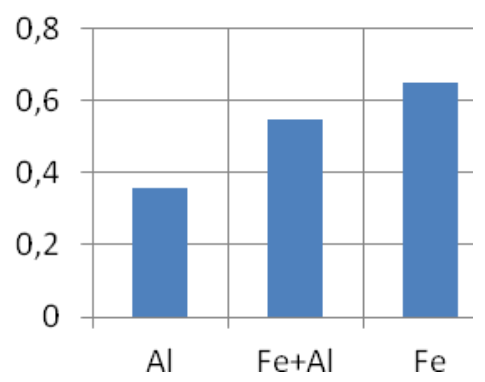

$a$

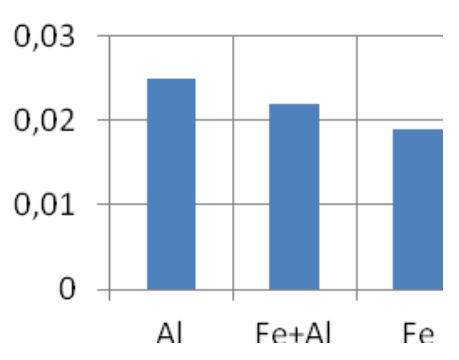

$\sigma$

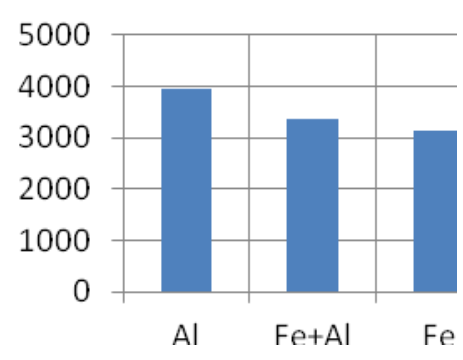

B

Рис. 5. Данные для стали: $a$ - время проплавления (c); $\sigma$ - скорость резания (м/с); $в$ - температура (K) 


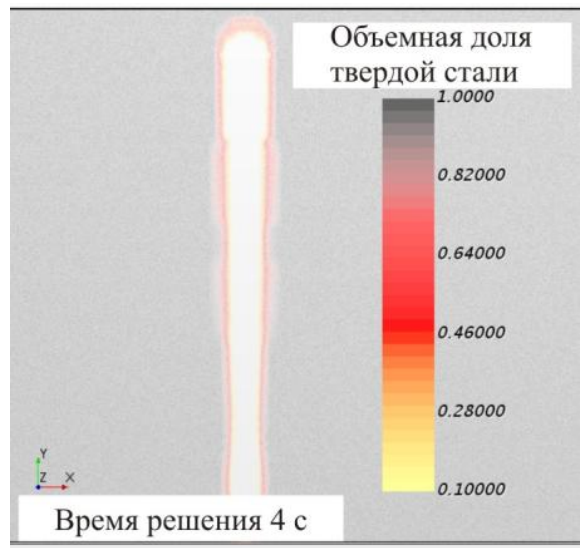

$a$

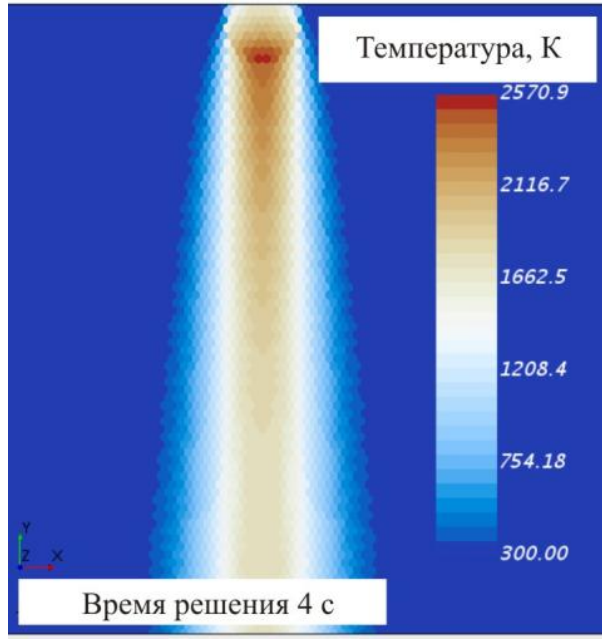

6

Рис. 6. Распределение температур и фаз в стальной пластине через 4 с после начала резания: $a$ - полевая картина твердой и жидкой фаз стальной пластины; $\sigma$ - полевая картина температур поверхности пластины

Для латуни, как и для нержавеющей стали, проведена серия расчетов, направленных на определение скорости проплавления листа, скорости движения копья и общего времени разрезания пластины. Расчеты проведены для аналогичных топливных композиций копий: чистый алюминий, чистое железо, алюминий и железо. Результаты представлены на рис. 7.
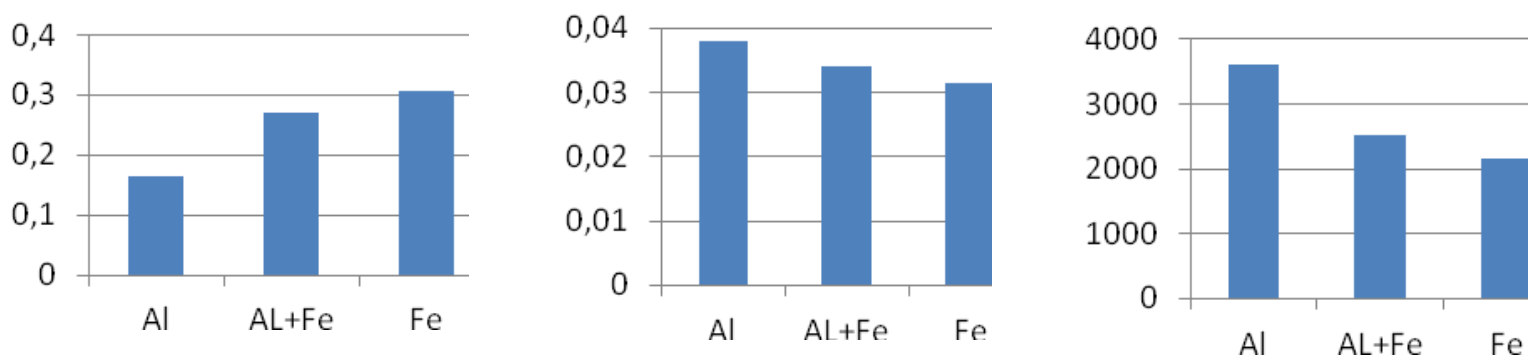

Рис. 7. Данные для латуни: $a$ - время проплавления (с); $\sigma$ - скорость резания (м/с); в - тепловой поток (Вт)
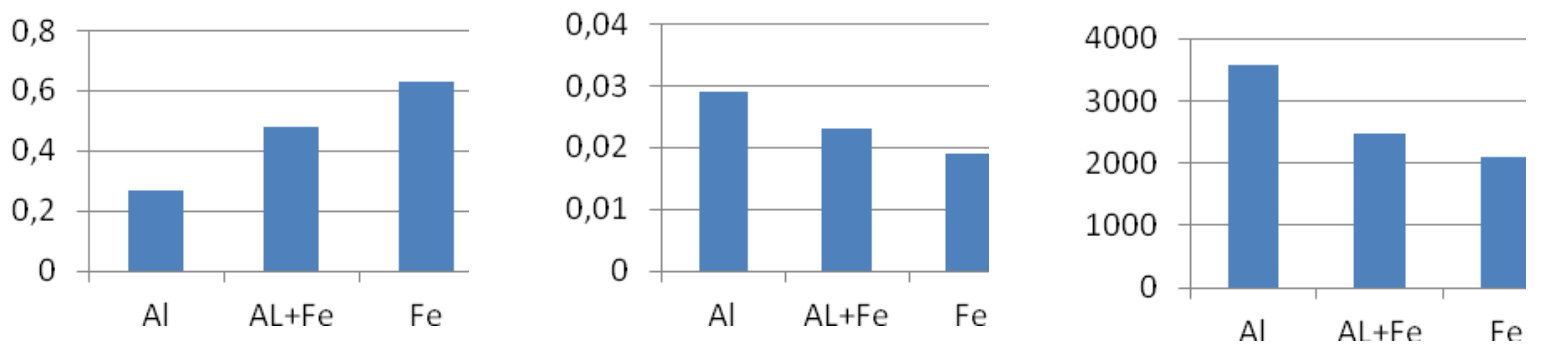

Рис. 8. Результаты для оксида алюминия: $a$ - время проплавления (c); $\sigma$ - скорость резания (м/c); в - тепловой поток $(\mathrm{BT})$

Первое важное замечание касается свойств латуни. Ввиду того, что скрытая теплота плавления и температуры солидуса- ликвидуса латуни значительно меньше, чем у нержавеющей стали, время проплавления заметно снижается. Так, для варианта с использо- 
ванием кислородного копья на чистом алюминии время проплавления снизилось в 2,17 раза (с 0,358 до 0,165 c). За счет свойств также выросла скорость резания (с 0,025 до 0,038 м/с) и уменьшилось общее время разрезания пластины.

Характер изменения исследуемых параметров при смене горючего остался прежним, напрямую зависящим от температуры горения. Нужно отметить, что при использовании метода моделирования без учета вытекания материала из зоны резания расплавленный материал начинает быстро переходить обратно в твердое состояние. При дальнейших расчетах и исследованиях это нужно учитывать, так как на переход материала из жидкой фазы в твердую тратится дополнительная энергия.

Говоря о результатах расчетов для оксида алюминия, можно отметить, что они занимают некоторое промежуточное положение по времени проплавления и скорости резания по сравнению с предыдущими вариантами. Для удобства сравнения результаты собраны в гистограммы на рис. 8.

Для апробации результатов численного моделирования были проведены огневые испытания кислородных копий с разной топливной композицией и для различных разрезаемых материалов. Основное значение здесь имеет анализ и сравнение данных, полученных при резке стальной пластины.
Огневые испытания проводились в Перми на производственной площадке ООО «Вторичные металлы» для пяти вариантов кислородных копий, отличающихся количеством алюминиевых проволок:

1) алюминий - 0 шт., железо - 19 шт. (0\% на $100 \%)$;

2) алюминий - 1 шт., железо - 18 шт. $(5,26 \%$ на $94,74 \%)$;

3) алюминий - 6 шт., железо - 13 шт. $(31,57 \%$ на $68,43 \%)$;

4) алюминий - 13 шт., железо - 6 шт. $(68,43 \%$ на $31,57 \%)$;

5) алюминий - 19 шт., железо - 0 шт. (100\% на $0 \%$ ).

Основа копья - трубка из низкоуглеродистой стали: $D_{\text {нар }}=15,0$ мм, $d_{\text {вн }}=12,0$ мм.

После огневых испытаний самих копий были проведены пробные резки различных образцов материалов (низкоуглеродистая сталь, нержавеющая сталь - 12X18Н10Т) и конструкций (швеллер, труба и т.п.). Для этого было использовано копье в варианте 3. Произведено сравнение двух способов разрезания образца из нержавеющей стали: кислородным копьем и традиционным кислородным резаком. Сравнение показало преимущество кислородного копья: традиционным кислородным резаком вообще не удалось разрезать образец из нержавеющей стали, в то время как кислородным копьем это надежно удавалось сделать (рис. 9).

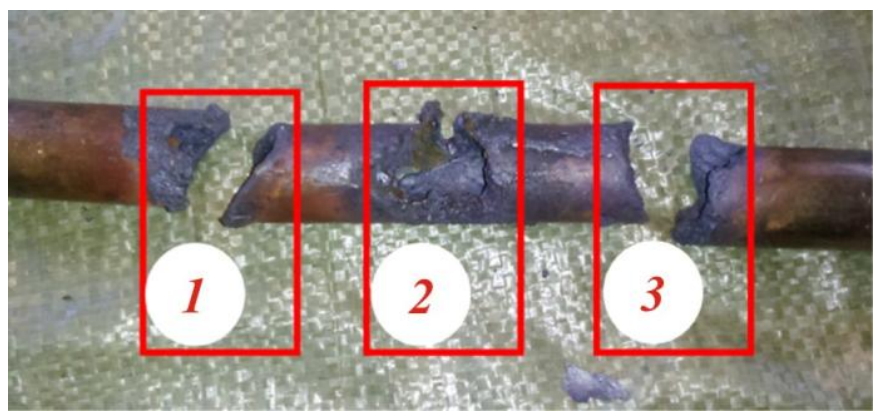

Рис. 9. Образец трубы из нержавеющей стали: 1, 3 - рез кислородным копьем с проволоками внутри; 2 - рез традиционным кислородным резаком

Проверка процесса резания различных материалов и конструкций показала высокую эффективность работы экспериментальными образцами копий, т.е. все поставленные на испытания образцы материалов и конструкций были разрезаны за время от 2 до 12 с в зависимости от толщины и габарита образца.
Стальная пластина (12X18H10T) толщиной порядка 1 мм также была разрезана кислородным копьем. Использовался вариант 3. Для него, согласно термодинамическим расчетам, температура горения в зависимости от количества кислорода окажется порядка 3300 К. При этом пластину удалось разрезать менее чем за 
2 с. Длина реза составила 100 мм по срединной линии (рис. 10).

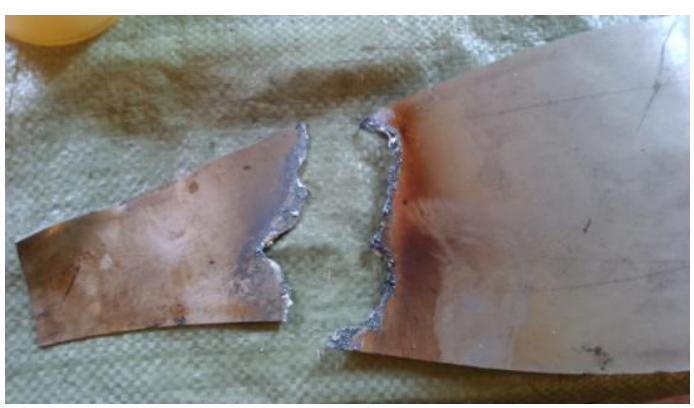

Рис. 10. Разрез нержавеющей стали

Таким образом, средняя скорость резания оказалась на уровне 0,05 м/с. При моделировании процесса резания на STAR-CCM+ в идеальных условиях было показано, что одинарное кислородное копье способно резать со скоростью $0,022 \mathrm{M} / \mathrm{c}$, а сдвоенное со скоростью $0,05 \mathrm{~m} / \mathrm{c}$.

Экспериментальное значение скорости резания расположилось между этими двумя значениями, что является хорошим результатом. Отклонения практических данных от расчетных обусловлены сложностью процесса го- рения и подготовки и контроля расхода окислителя и горючего в реальных условиях. Так, например, давление в кислородных баллонах при резании будет уменьшаться, из-за чего реальная температура горения не будет постоянной величиной, как и тепловой поток от копья.

С другой стороны, при численных расчетах принято довольно много допущений, несомненно, влияющих на точность решения. Но с учетом поставленной цели - провести качественную оценку процесса резания кислородным копьем - полученные результаты являются удовлетворительными и позволяют перейти к более глубоким исследованиям. Следует также отметить, что экспериментальная разделительная резка различных конструкций (пластин, труб, швеллеров) показала существенное преимущество разработанного кислородного копья перед традиционным кислородным резаком, в особенности для образцов из нержавеющей стали.

Статья написана на основе материалов НИОКР, выполненной по договору № 241ГС 1/8708 от 12.02.2015 ООО МИП «Инновачии» с федеральным Фондом содействия инновациям (https://fasie.ru).

\section{Библиографический список}

1. Технология конструкционных материалов: учеб. для машиностроительных специальностей вузов / А.М. Дальский, Т.М. Барсукова, Л.Н. Бухаркин [и др.]; под общ. ред. А.М. Дальского. - 5-е изд., испр. - М.: Машиностроение, 2003. -512 c.

2. Стеклов О.И. Основы сварочного производства: учеб. пособие для техн. училищ. - М.: Высш. шк., 1981. $-160 \mathrm{c}$

3. Сварка и резка материалов: учеб. пособие для нач. проф. образования / М.Д. Банов, Ю.В. Казаков, М.Г. Козулин [и др.]; под ред. Ю.В. Казакова. - 3-е изд., стер. - М.: Академия, 2003. - 400 с.

4. Овчинников В.В. Технология газовой сварки и резки металлов: учеб. для студ. учреждений сред. проф. образ. - 5-е изд., стер. - М.: Академия, 2016. - 240 с.

5. Казаков С.И. Сварка плавлением и термическая резка металлов: учеб. пособие. - Курган: Изд-во Курган. гос. ун-та, 2014. - 365 с.

6. Безопасность атомных станций / А.В. Носовский, В.Н. Васильченко, А.А. Ключников, Я.В. Ященко; под ред. А.В. Носовского. - Киев: Техника, 2005. - 288 с.

7. Набокина Т.П. Анализ технологии утилизационной фрагментации планеров воздушных судов // Авиационно-космическая техника и технология. - 2005. - № 2(18). - С. $23-25$.

8. Малышев В.А., Васильченко Д.Г. Техническое решение для подачи воздуха пострадавшим, оказавшимся в заваленных сооружениях // Современные проблемы в транспортно-технологической и аварийно-спасательной технике в системе МЧС: сб. тр. секции № 10 XXVIII Междунар. науч.-практ. конф. «Предотвращение. Спасение. Помощь», г. Химки, 22 марта 2018 г. - М., 2018. - С. 47-54.

9. Технология и оборудование сварки плавлением и термической резки: учеб. для вузов / под ред. А.И. Акулова. - 2-е изд., испр. и доп. - М.: Машиностроение, 2003. - 560 с.

10. Буталов В.А. Технология металлов. - 3-е изд., перераб. и доп. - М.: Гос. науч.-техн. изд-во по черн. и цвет. металлургии, 1962. -512 с.

11. Анисимова М.А., Князева А.Г. Модель кислородной резки металлической пластины с учетом химического тепловыделения // Физика горения и взрыва. - 2016. - Т. 52, № 1. - С. 60-69. 
12. Результаты экспериментального исследования процессов горения кислородного копья и определение зависимости основных выходных характеристик от входных параметров / Ю.В. Цветков, Г.А. Цветков, Р.В. Цветков [и др.] // Вестник Пермского национального исследовательского политехнического университета. Аэрокосмическая техника. - 2019. - № 59. - С. 38-50.

13. Александров В.М. Материаловедение и технология конструкционных материалов: учеб. пособие. Ч. 1. Материаловедение. Стандарт третьего поколения / Север. (Арктический) федер. ун-т. - Архангельск, 2015. - $327 \mathrm{c}$.

14. Специальные стали: учеб. пособие / Е.В. Братковский, А.В. Заводяный, А.Н. Шаповалов, Е.А. Шевченко; НФ НИТУ «МИСиС». - Новотроицк, 2013. - 87 с.

15. Пирумов У.Г., Росляков Г.С. Численные методы газовой динамики: учеб. пособие для студентов втузов. - М.: Высш. шк., 1987. - 232 с.

16. Ворожцов Е.В. Разностные методы решения задач механики сплошных сред: учеб. пособие. Новосибирск: Изд-во НГТУ, 1998. - 86 с.

17. Газовая динамика. Избранное: в 2 т. / под ред. А.Н. Крайко. - М.: Физико-математическая литература, 2001. - T. 2. - 768 c.

18. Chan S.H., Cho D.H., Kocamustafaogullari G. Melting and solidification with internal radiative transfer - a generalized phase change model // International Journal of Heat and Mass Transfer. - 1983. - No. 26(4). P. 621-633.

19. Swaminathan C.R., Voller V.R. A general enthalpy method for modeling solidification processes // Met. Trans. B. - 1992. - No. 22(B). - P. 651-664.

20. Voller V.R. An overview of numerical methods for solving phase change problems // Advances in Numerical Heat Transfer / eds.W.J. Minkowycz and E.M. Sparrow. - Taylor \& Francis, 1997. - P. 341-378.

21. Исаченко В.П., Осипова В.А., Сукомел А.С. Теплопередача: учеб. для вузов - 3-е изд., перераб. и доп. - М.: Энергия, 1975. - 488 с.

22. Марочник сталей и сплавов / под ред. А.С. Зубченко. - 2-е изд., перераб. и доп. - М.: Машиностроение, 2003. - 784 с.

23. Ямпольский А.М., Ильин В.А. Краткий справочник гальванотехника. - М.; Л.: Гос. науч.-техн. изд-во машиностроит. лит., 1962. - 244 с.

24. Физико-химические свойства окислов: справ. / под ред. Г.В. Самсонова. - 2-е изд. - М.: Металлургия, 1978. - 472 с.

\section{References}

1. Dal'skii A.M., Barsukova T.M., Bukharkin L.N. [et al]. Tekhnologiia konstruktsionnykh materialov. Uchebnik dlia mashinostroitel'nykh spetsial'nostei vuzov; Ed by A.M. Dal'skogo. 5-e izd., ispravlennoe. M.: Mashinostroenie, 2003. 512 p.

2. Steklov O.I. Osnovy svarochnogo proizvodstva: M.: Vyssh. shkola, 1981. 160 p.

3. Banov M.D., Kazakov Iu.V., Kozulin M.G. [et al] Svarka i rezka materialov: Ucheb. posobie dlia nach. prof. obrazovaniia. Ed by Iu.V. Kazakova. 3-e izd., ster. M.: Izdatel'skii tsentr “Akademiia”, 2003. 400 p.

4. Ovchinnikov V.V. Tekhnologiia gazovoi svarki i rezki metallov. 5-e izd., ster. M.: Akademiia, 2016. 240 p.

5. Kazakov S.I. Svarka plavleniem i termicheskaia rezka metallov. Kurgan: Izd-vo Kurganskogo gos. un-ta, 2014. 365 p.

6. Nosovskii A.V., Vasil'chenko V.N., Kliuchnikov A.A., Iashchenko Ia.V. Bezopasnost' atomnykh stantsii; Ed by A.V. Nosovskogo. Kiev: Tekhnika, 2005. 288 p.

7. Nabokina T.P. Analiz tekhnologii utilizatsionnoi fragmentatsii planerov vozdushnykh sudov // Aviatsionno-kosmicheskaia tekhnika i tekhnologiia. 2005. no 2(18). pp. 23-25.

8. Malyshev V.A., Vasil'chenko D.G. Tekhnicheskoe reshenie dlia podachi vozdukha postradavshim, okazavshimsia v zavalennykh sooruzheniiakh. Sovremennye problemy v transportno-tekhnologicheskoi $i$ avariinospasatel'noi tekhniki v sisteme MChS: sbornik trudov sektsii № 10 XXVIII Mezhdunarodnoi nauch.-prak. konf. "Predotvrashchenie. Spasenie. Pomoshch"', Khimki, 22 marta 2018. FGBVOU VO AGZ MChS Rossii. 2018, pp. 47-54.

9. Tekhnologiia i oborudovanie svarki plavleniem i termicheskoi rezki: uchebnik dlia vuzov. Ed by A.I. Akulova. Izd. 2-e ispr. i dop. M.: Mashinostroenie, 2003. 560 p.

10. Butalov V.A. Tekhnologiia metallov. Izd. 3-e, pererab. i dop. M.: Gosudarstvennoe nauchnotekhnicheskoe izdatel'stvo po chernoi i tsvetnoi metallurgii, 1962. 512 p. 
11. Anisimova M.A., Kniazeva A.G. Model' kislorodnoi rezki metallicheskoi plastiny s uchetom khimicheskogo teplovydeleniia. Fizika goreniia i vzryva. 2016, Vol. 52, no 1, pp. 60-69.

12. Tsvetkov Iu.V., Tsvetkov G.A., Tsvetkov R.V. [et al]. Rezul'taty eksperimental'nogo issledovaniia protsessov goreniia kislorodnogo kop'ia i opredelenie zavisimosti osnovnykh vykhodnykh kharakteristik ot vkhodnykh parametrov. Vestnik Permskogo natsional'nogo issledovatel'skogo politekhnicheskogo universiteta. Aerokosmicheskaia tekhnika. 2019, no 59, pp. 38-50.

13. Aleksandrov V.M. Materialovedenie i tekhnologiia konstruktsionnykh materialov. Uchebnoe posobie. Chast' 1. Materialovedenie. Standart tret'ego pokoleniia. Arkhangel'sk: Severnyi (Arkticheskii) federal'nyi un-t, 2015. 327 p.

14. Bratkovskii E.V., Zavodianyi A.V., Shapovalov A.N., Shevchenko E.A. Spetsial'nye stali: Uchebnoe posobie. Novotroitsk: NF NITU “MISiS”, 2013. 87 s.

15. Pirumov U.G., Rosliakov G.S. Chislennye metody gazovoi dinamiki: Ucheb. posobie dlia studentov vtuzov. M.: Vyssh. shk., 1987. 232 p.

16. Vorozhtsov E.V. Raznostnye metody resheniia zadach mekhaniki sploshnykh sred: Novosibirsk: Izd-vo NGTU, 1998. 86 p.

17. Gazovaia dinamika. Izbrannoe: V 2 t. Ed by A.N. Kraiko. M.: Fiziko-matematicheskaia literatura, 2001. Vol. 2, 768 p.

18. Chan S.H., Cho D.H., Kocamustafaogullari G. Melting and solidification with internal radiative transfer - a generalized phase change model. International Journal of Heat and Mass Transfer. 1983, no 26(4), pp. 621-633.

19. Swaminathan C.R., Voller V.R. A general enthalpy method for modeling solidification processes. Met. Trans. B. 1992, no 22(B), pp. 651-664.

20. Voller V.R. An overview of numerical methods for solving phase change problems. Advances in Numerical Heat Transfer, W.J. Minkowycz and E.M. Sparrow Eds., Taylor \& Francis. 1997. pp. 341-378.

21. Isachenko V.P., Osipova V.A., Sukomel A.S. Teploperedacha. Uchebnik dlia vuzovю. Izd. 3-e, pererab. i dop. M.: Energiia, 1975. 488 s.

22. Marochnik stalei i splavov. Ed by A.S. Zubchenko. 2-e izd. pererab. i dop. M.: Mashinostroenie, 2003. $784 \mathrm{p}$.

23. Iampol'skii A.M., Il'in V.A. Kratkii spravochnik gal'vanotekhnika M.-L.: Gosudarstvennoe nauchnotekhnicheskoe izdatel'stvo mashinostroitel'noi literatury, 1962. $244 \mathrm{p}$.

24. Fiziko-khimicheskie svoistva okislov: Spravochnik. Ed by G.V. Samsonova. 2 izd. M.: Metallurgiia, 1978. $472 \mathrm{p}$.

\section{Об авторах}

Цветков Юрий Викторович (Пермь, Россия) - инженер, предприниматель в инновационной сфере, учредитель и директор ООО МИП «Инновации» (614010, г. Пермь, ул. Героев Хасана, д. 12, e-mail: cuvvt@perm.ru).

Савин Максим Анатольевич (Пермь, Россия) - кандидат технических наук, доцент кафедры «Сварочное производство, метрология и технология материалов» ФГАОУ ВО ПНИПУ (614990, г. Пермь, Комсомольский пр., д. 29, e-mail: abins@pstu.ru).

Василенко Владимир Данилович (Пермь, Россия) - заведующий лабораторией кафедры «Сварочное производство, метрология и технология материалов» ФГАОУ ВО ПНИПУ (614990, г. Пермь, Комсомольский пр., д. 29, e-mail: abins @ pstu.ru).

Цветков Геннадий Александрович (Пермь, Россия) - доктор технических наук, профессор кафедры «Безопасность жизнедеятельности» ФГАОУ ВО ПНИПУ (614990, г. Пермь, Комсомольский пр., д. 29 , e-mail: bg@pstu.ru).

Вахрамеев Евгений Иванович (Пермь, Россия) - кандидат технических наук, доцент кафедры «Сварочное производство, метрология и технология материалов» ФГАОУ ВО ПНИПУ (614990, г. Пермь, Комсомольский пр., д. 29, e-mail: abins@pstu.ru).

\section{About the authors}

Jurii V. Tsvetkov (Perm, Russian Federation) - Engineer, Businessman for Innovation Sector, Founder and Director General, LLC “Small Innovative Enterprise "Innovation” (12, Geroyev Khasana st., Perm, 614010, Russian Federation; e-mail: cuv-vt@perm.ru). 
Maxim A. Savin (Perm, Russian Federation) - Ph.D. in Technical Sciences, Associate Professor of Welding Production, Metrology and Technology of Materials Department, Perm National Research Polytechnic University (29, Komsomolskiy av., Perm, 614990, Russian Federation; e-mail: abins@ @stu.ru).

Vladimir D. Vasilenko (Perm, Russian Federation) - Laboratory Chief of Welding Production, Metrology and Technology of Materials Department, Perm National Research Polytechnic University (29, Komsomolskiy av., Perm, 614990, Russian Federation; e-mail: abins@pstu.ru).

Gennadii A. Tsvetkov (Perm, Russian Federation) - Ph.D. in Technical Sciences, Professor of Civil Protection Department, Perm National Research Polytechnic University (29, Komsomolskiy av., Perm, 614990, Russian Federation; e-mail: bg@pstu.ru).

Evgenij I. Vahrameev (Perm, Russian Federation) - Ph.D. in Technical Sciences, Associate Professor of Welding Production, Metrology and Technology of Materials Department, Perm National Research Polytechnic University (29, Komsomolskiy av., Perm, 614990, Russian Federation; e-mail: abins @ pstu.ru).

Получено 17.05.2021 